\section{Influence of gender and age on distal femur shape. Are there any relevant differences?}

\author{
Fabrício B. Loures, ${ }^{* 1,2}$ Thales G. Felippe, ${ }^{2}$ Matheus P. A. Góes, ${ }^{2}$ Rogério F. A. Góes, ${ }^{2}$ André Kinder, ${ }^{3}$ \\ Pedro José Labronici ${ }^{4}$
}

\begin{abstract}
Introduction: Osteoarthritis (OA) of the knee is a chronic, progressive, and highly prevalent disease. When the disease reaches its final stage, with clinical symptoms refractory to treatment or disabling deformity, surgical treatment becomes the option via total knee arthroplasty (TKA). The distal femur has a fundamental role in the success of TKA, being directly involved in joint stability, range of motion, and normal gait. Objective: Evaluate the possible sex differences in the shape of the distal femur and the age group influence on morphometry. Methods: Five measurements on 124 knees were evaluated using magnetic resonance imaging, 62 male and 62 female. The age ranged between 40 and 80 years, and the patients were divided into two age groups. Three factors were analyzed, allowing the bone classification regarding its width, shape, and symmetry. Results: The male group showed absolute measurements greater than the female, but there were no sex differences in the shape of the knee. Younger patients had more trapezoidal knees and a higher rate of asymmetry between condyles. After analyzing the factors, regarding their width, 31 knees were considered standard, 47 narrow, and 46 wide. As for the shape of the knee, 12 were considered standard, 58 rectangular, and 54 trapezoidal. About the condyles symmetry, 23 were classified as symmetrical and 101 asymmetrical. There was a great interpersonal variation in the shape of the knee, regardless of the sex. Conclusion: The shape of the distal femur presents great interpersonal variation, going beyond the simple division between wide or narrow. This variation is influenced by the patients' age, but not the sex. Level of evidence: 4
\end{abstract}

Keywords: Anthropometry; Arthroplasty; Sex; Knee; Magnetic resonance.

\section{Introduction}

Osteoarthritis (OA) of the knee is a chronic, progressive, and highly prevalent disease. About $33 \%$ of the Brazilian population over 25 years, corresponding to 39 million people, have some OA type. Due to anatomical and biomechanical factors, the joint most

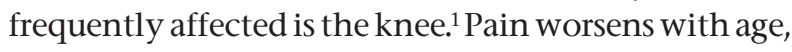
and among those over 75 years, $56.6 \%$ of OA patients have symptoms. Clinical manifestations are more frequent in females than in male patients. $(47.6 \%$ and $37.4 \%$ respectively). ${ }^{2}$

When the disease reaches its final stage, with clinical symptoms refractory to treatment or disabling
1. Unidade Docente Assistencial de Ortopedia, Hospital Universitário Pedro Ernesto, Universidade do Estado do Rio de Janeiro. Rio de Janeiro, RJ, Brazil.

2. Serviço de Ortopedia, Hospital Santa Teresa. Petrópolis, RJ, Brazil.

3. Disciplina de Radiologia e Diagnóstico por Imagem, Faculdade de Medicina de Petrópolis. Petrópolis, RJ, Brazil.

4. Departamento de Cirurgia Especializada, Faculdade de Medicina, Universidade Federal Fluminense. Niterói, RJ, Brazil.

* Correspondence address:

Rua Dr. Nelson de Sá Earp, 111/901

Petrópolis, RJ, Brazil.

CEP: 25680-195.

E-mail: fbolpato@gmail.com

ORCID: https://orcid.org/0000-0001-9816-6065

BJHBS, Rio de Janeiro, 2021;20(1):19-26

DOI: $10.12957 /$ bjhbs.2021.59742

Received on 02/13/2021. Approved on 03/04/2021.

deformity, surgical treatment becomes the option. Total knee arthroplasty (TKA) has been performed since the end of the 19th century; however, it has become popular since the 1970s. ${ }^{3}$ Currently, TKA is the most commonly performed procedure in hospitalized patients in the USA, with around 700,000 surgeries per year. ${ }^{4}$ Projections indicate that this number should reach 1.26 million procedures in $2030 .{ }^{5}$ Brazil, despite the deficit of assistance, presents an increasing demand, driven by the population aging and obesity ${ }^{6}$

A prosthesis must resemble the knee's anatomy for a joint replacement to achieve its goal of restoring function with maximum durability. Inconsistencies between the implant and the resected bone increase the surgery complexity and compromise the clinical outcome. The literature reveals that incompatibilities above acceptable occur between $28 \%$ and $84 \%$ of cases. ${ }^{8,9}$

The distal femur has a fundamental role in the success of TKA, being directly involved in joint stability, range of motion, and normal gait. Despite being the target of many anatomical studies, the factors related to its variability are still little known. Several studies have attempted to find in the patients' sex the explanation 


\section{Original article}

for unsatisfactory clinical results after TKA.10,11

This study's main objective was to evaluate the possible sex differences in the shape of the distal femur. The secondary objective was to assess whether there is an age group influence on morphometry. The study hypothesized that there is a sex difference in the shape of the distal femur, and anatomical changes could be caused by age.

\section{Materials and methods}

After approval by the Research Ethics Committee of our institution, the shape of the distal femur was assessed using Magnetic Resonance Imaging (MRI) files. As main objective to compare the measurements and the shape of the knees between male and female in two different age groups, considering Brazil's prevalence of $5.2 \%$ with OA of the knee, the significance level of $5 \%$ $(\alpha)$, and the power of statistical tests of $80 \%(1-\beta)$, according to Triola, ${ }^{12}$ would be necessary, at least 30 individuals in each group, totaling 120 knees as sample size.

The examinations performed in patients between 40 and 80 years at the institution between July and December 2017 were evaluated. The same age group, of both sexes and with exams within the desired standard were also included. Patients with a history of fracture or previous knee surgery, bone defects, or tumors were excluded from the study.



Figure 1. The knee axial image, with the distal femoral cut simulated using magnetic resonance imaging Source: The autors (2017).
The study's lead author (FBL) simulated the distal femoral cut at $9 \mathrm{~mm}$ from the joint edge, as occurs during the bone surface preparation for prosthesis implantation. The knee axial image was used with the aid of the Osirix ${ }^{\circledR}$ Software(Figure 1). Five measurements were made on the distal femur's image (medial and lateral condyles heights, total femur width on the transepicondylar axis, and at points corresponding to $25 \%$ and $75 \%$ of its height) (Figure 2). The measurements were performed twice, and the arithmetic means were documented for analysis.

Four different groups were created regarding age and sex: men and women between 40-60 and 60-80. Three factors between measurements were compared: A) factor between the total femur width on the transepicondylar axis (4) and the lateral condyle height (1), to define whether the femur would be classified as wide or narrow; B) factor between the femur width at the point $75 \%$ (3) and 25\% (5) of its height, to define whether the femur would be trapezoidal or rectangular and C) factor between the height of the lateral (1) and medial condyle (2) to define whether the femur would be symmetrical or asymmetrical. After defining the factors, the confidence interval (CI) was calculated around the mean, and the femurs within that interval were considered normal. These factors are shown in Figure 3.

An identical protocol was used to perform MRI on

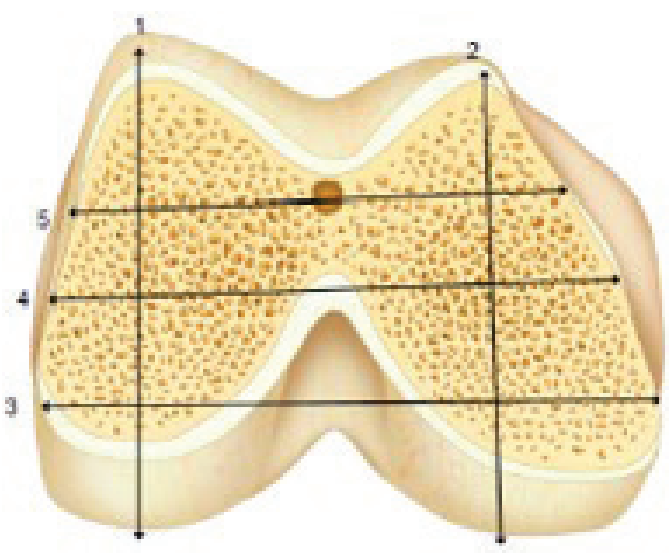

Figure 2. Measurements on the distal femur's image. 1 lateral condyle height, $\mathbf{2}$ - medial condyle height, $\mathbf{3}$ - total femur width at the point $75 \%$ of its height, 4 - total femur width on the transepicondylar axis, 5 - total femur width at the point $25 \%$ of its height Source: The autors (2017). 
all analyzed knees. The examinations were performed in a 1.5T apparatus (Magneton Essenza ${ }^{\circledR}$; Siemens, Germany). The patient was in the supine position and the knee relaxed in full extension or minimal flexion $\left(<15^{\circ}\right)$ for more comfort. The following sequences were performed: sagittal, proton density-weighted with fat suppression (repetition time (TR): $2800 \mathrm{~ms}$, echo time (TE): $35 \mathrm{~ms}$, thickness: $4 \mathrm{~mm}$, field of view (FOV): 160 / 160 mm, and matrix: 230/320); sagittal, T1-weighted (TR: 540 ms, TE: 13 ms, thickness: 4 mm, FOV: 160/160 mm, matrix:230/384); coronal, proton density-weighted with fat suppression (TR: $2040 \mathrm{~ms}$, TE: $32 \mathrm{~ms}$, thickness: $4 \mathrm{~mm}$, FOV: 160/160 mm, matrix: 224/320); and axial, proton density-weighted with fat suppression (TR: 3140 ms, TE: 35 ms, thickness: 4 mm FOV: 160/160 mm, matrix: 192/320).

The measures of central tendency and dispersion were presented in descriptive tables. The inferential analysis was composed by the two-way analysis of variance (two-way ANOVA) to evaluate the main effect of the age group, sex, and the respective interaction between sexes and age group in the evaluated measures. The student's t-test analyzed the comparison of measures and the factors between pairs for independent samples; $5 \%$ of significance level was adopted. The statistical analysis was processed with the aid of SAS 6.11 software (SAS Institute, Inc., Cary, North Carolin, USA).

\section{Results}

One hundred twenty-four knees from 124 patients were analyzed, 62 male and 62 female. The measurements showed a normal distribution. Measurement statistics, divided by age group, are shown in Table 1.

The male and female samples showed similarity concerning age $(p=0.43)$. Male patients had all measures greater than female, but no factors were significantly different. The values with the respective statistical tests are shown in Table 2.

When compared by age group, the measurements were similar for both groups. The factors $3 / 5$ and $1 / 2$ were significantly higher for younger patients. The comparisons are shown in Table 3.

After analyzing the factors, 31 knees were considered standard, 47 narrow, and 46 wide. Regarding the shape, 12 knees were considered standard, 58 rectangular, and 54 trapezoidal. About the condyles symmetry, 23 were classified as symmetrical and 101 asymmetrical. The factors relating to the mean and its respective confidence interval are shown in Table 4.

\section{Discussion}

TKA is one of the most successful surgeries of the century. However, it still shows dissatisfaction rates ranging from 17 to $41 \%$ of operated patients. ${ }^{13}$ Several anatomical studies reveal incompatibilities between the implant and the resected bone that are much higher than expected. ${ }^{8}$ The distal femur morphometry and the factors that influence its variations have been the subject of constant research, seeking to understand the best way to mimic the knee's anatomy and biomechanics. $[9,14]$ The shape of the knee varies widely, and the sizes of the available components are limited, mainly due to economic reasons. ${ }^{15}$ The great interpersonal variation demonstrated in the research shows the surgeon's practical difficulties to combine the implant with the resected bone, increasing the surgery complexity and compromising the clinical and functional outcome.

In the present study, male patients had all dimensions significantly greater than female, which was similar to what was found by Lonner et al., ${ }^{16}$ Han et al. ${ }^{17}$ and Loures et al. ${ }^{18}$ Bonnin et al. ${ }^{9}$ studied the shape of 114 knees using computed tomography and compared it with the size of 12 implant manufacturers. They found an incompatibility of $84 \%$ in female
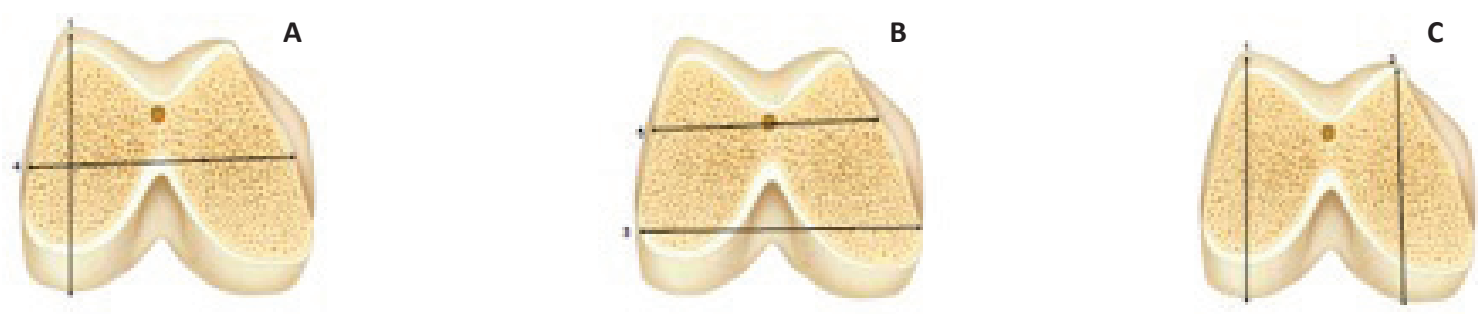

Figure 3. A) measures to define if the femur is wide or narrow B) trapezoidal or rectangular, and C) symmetrical or asymmetrical

Source: The autors (2017). 


\section{Original article}

Table 1. Measurement statistics divided by age group

\begin{tabular}{|c|c|c|c|c|c|c|c|c|c|}
\hline Variable & $\mathbf{N}$ & Mean & SD & Median & Q1 & - & Q3 & Minimum & Maximum \\
\hline \multicolumn{10}{|l|}{40 - 59 years } \\
\hline Age (years) & 60 & 48.6 & 5.2 & 47 & 44.3 & - & 53.0 & 40.0 & 59.0 \\
\hline Measure 1 & 60 & 61.5 & 4.7 & 60.4 & 57.9 & - & 65.7 & 54.1 & 73.8 \\
\hline Measure 2 & 60 & 58.7 & 4.8 & 58.2 & 54.9 & - & 63.1 & 50.6 & 72.8 \\
\hline Measure 3 & 60 & 76.8 & 5.9 & 76.3 & 72.8 & - & 81.1 & 66.7 & 94.9 \\
\hline Measure 4 & 60 & 74.1 & 5.8 & 74.1 & 69.7 & - & 78.4 & 63.9 & 91.3 \\
\hline Measure 5 & 60 & 62.0 & 5.3 & 61.9 & 57.6 & - & 66.1 & 52.7 & 74.1 \\
\hline Factor (4) / (1) & 60 & 1.207 & 0.059 & 1.211 & 1.166 & - & 1.237 & 1.042 & 1.337 \\
\hline Factor (3) / (5) & 60 & 1.241 & 0.058 & 1.238 & 1.190 & - & 1.296 & 1.164 & 1.386 \\
\hline Factor (1) / (2) & 60 & 1.048 & 0.033 & 1.044 & 1.025 & - & 1.074 & 0.952 & 1.145 \\
\hline \multicolumn{10}{|l|}{$60-79$ years } \\
\hline Age (years) & 64 & 66.2 & 5.3 & 64 & 62.0 & - & 71.0 & 60.0 & 77.0 \\
\hline Measure 1 & 64 & 60.9 & 4.6 & 60.5 & 58.1 & - & 63.7 & 50.8 & 72.6 \\
\hline Measure 2 & 64 & 59.4 & 3,8 & 58.8 & 56.8 & - & 61.9 & 517 & 71.0 \\
\hline Measure 3 & 64 & 75.0 & 6.6 & 74.5 & 70.7 & - & 79.8 & 62.1 & 93.2 \\
\hline Measure 4 & 64 & 73.9 & 6.0 & 739 & 69.2 & - & 76.9 & 62.5 & 88.2 \\
\hline Measure 5 & 64 & 61.9 & 5.6 & 62.0 & 57.3 & - & 65.2 & 52.3 & 75.5 \\
\hline Factor $(4) /(1)$ & 64 & 1.216 & 0.071 & 1.213 & 1.173 & - & 1.256 & 1.059 & 1.484 \\
\hline Factor (3)/(5) & 64 & 1.212 & 0.062 & 1.221 & 1.169 & - & 1.252 & 1.076 & 1.357 \\
\hline Factor (1)/(2) & 64 & 1.025 & 0.042 & 1.027 & 0.994 & - & 1.056 & 0.924 & 1.115 \\
\hline
\end{tabular}

Legend: SD: standard deviation; Q1: 1st quartile; Q3: 3rd quartile.

Source: Institution's data. (2017)

patients and 54\% in male. The risk of excess implant (overhang) was higher in trapezoidal-shaped femurs, which can be explained by the implant configuration, which is mostly rectangular. The younger group had a higher incidence of trapezoidal femurs. The same variation regarding the age was also found by Han et al..$^{17}$ and Li et al. ${ }^{19}$ in their anthropometric study after evaluating a significant number of joints. Fortunately, young patients are rarely submitted to TKA; however, this anatomical difference should be considered when surgical treatment becomes necessary. Research for the development of new implants should be based on an elderly population, as they are the target audience for arthroplasties, and the shape of the distal femur varies with age.

The patellofemoral joint is of great importance for transferring quadriceps muscle strength during both eccentric and concentric contractions. The patellae increase the distance from the extensor mechanism to the femoral rotation center, raising the muscular lever arm..$^{20}$ Maintaining this distance after TKA is essential, especially in elderly patients who mostly have sarcope- 
Table 2. Comparison between sexes

\begin{tabular}{|c|c|c|c|c|c|c|c|}
\hline \multirow{2}{*}{$\begin{array}{l}\text { Variable } \\
\text { Age (years) }\end{array}$} & \multicolumn{3}{|c|}{ Male $(n=62)$} & \multicolumn{3}{|c|}{ Female $(n=62)$} & \multirow{2}{*}{$\begin{array}{c}\boldsymbol{p} \text { value } \\
0.43\end{array}$} \\
\hline & 56.9 & & 10.5 & 58.4 & & 10.0 & \\
\hline Measure 1 & 63.9 & \pm & 4.2 & 58.4 & \pm & 3.2 & $<0.0001$ \\
\hline Measure 2 & 61.3 & \pm & 4.2 & 56.8 & \pm & 3.2 & $<0.0001$ \\
\hline Measure 3 & 80.2 & \pm & 5.0 & 71.5 & \pm & 4.1 & $<0.0001$ \\
\hline Measure 4 & 77.7 & \pm & 5.0 & 70.4 & \pm & 4.1 & $<0.0001$ \\
\hline Measure 5 & 65.7 & \pm & 4.4 & 58.3 & \pm & 3.6 & $<0.0001$ \\
\hline Factor (4) / (1) & 1.218 & \pm & 0.077 & 1.204 & \pm & 0.050 & 0.25 \\
\hline Factor (3) / (5) & 1.223 & \pm & 0.059 & 1.229 & \pm & 0.064 & 0.57 \\
\hline Factor (1) / (2) & 1.042 & \pm & 0.033 & 1.030 & \pm & 0.044 & 0.084 \\
\hline
\end{tabular}

Mean \pm standard deviation. Student T-test for independent samples.

Values in bold indicate a statistically significant difference.

Source: Institution's data (2017).

Table 3. Comparison between age groups

\begin{tabular}{|c|c|c|c|c|c|c|c|}
\hline \multirow{2}{*}{$\begin{array}{l}\text { Variable } \\
\text { Measure } 1\end{array}$} & \multicolumn{3}{|c|}{$40-59$ years $(n=60)$} & \multicolumn{3}{|c|}{$60-79$ years $(n=64)$} & \multirow{2}{*}{$\frac{p \text { value }}{0.46}$} \\
\hline & 61.5 & \pm & 4.7 & 60.9 & \pm & 4.6 & \\
\hline Measure 2 & 58.7 & \pm & 4.8 & 59.4 & \pm & 3.8 & 0.42 \\
\hline Measure 3 & 76.8 & \pm & 5.9 & 75.0 & \pm & 6.6 & 0.11 \\
\hline Measure 4 & 74.1 & \pm & 5.8 & 73.9 & \pm & 6.0 & 0.84 \\
\hline Measure 5 & 62.0 & \pm & 5.3 & 61.9 & \pm & 5.6 & 0.93 \\
\hline Factor (4) / (1) & 1.207 & \pm & 0.059 & 1.216 & \pm & 0.071 & 0.45 \\
\hline Factor (3) / (5) & 1.241 & \pm & 0.058 & 1.212 & \pm & 0.062 & 0.009 \\
\hline Factor (1) / (2) & 1.048 & \pm & 0.033 & 1.025 & \pm & 0.042 & 0.001 \\
\hline
\end{tabular}

Values in bold indicate a statistically significant difference.

Source: Institution's data (2017).

nia. ${ }^{21}$ Femurs were asymmetrical in $81 \%$ of cases, which can directly influence the surgery outcome. Prostheses larger than the condyles lead to excessive filling, which can cause pain and a limited range of motion. ${ }^{22}$ Smaller implants, on the other hand, may cause a decrease in the extension force or instability in knee flexion. ${ }^{23}$ The condyles asymmetry can also hinder the correct positioning of the rotational femoral implant, leading to clinical consequences. ${ }^{24}$

Mahfouz et al. ${ }^{25}$ studied 1000 knees, 80 of which were
African-American, 80 Asians, and 860 Caucasians. They found significant differences in the distal femur morphology regarding ethnicity. The studied patients were not evaluated concerning skin color due to a Brazilian population sample. Genetic studies have shown a fragile relationship between genotype and skin color in this population. After centuries of miscegenation, the skin color phenotype has little or no value in medical practice. ${ }^{26}$

There is a constant debate whether there is a difference in the distal femur morphometry between men 


\section{Original article}

Table 4. The shape of the knee's classification regarding its factors

\begin{tabular}{|c|c|c|c|c|c|c|c|c|c|}
\hline \multirow[t]{2}{*}{ Variable } & \multirow[t]{2}{*}{$\mathbf{N}$} & \multicolumn{3}{|c|}{$95 \% \mathrm{Cl}$} & \multicolumn{5}{|c|}{ Number of patients according to intervals } \\
\hline & & Mean & $\begin{array}{l}\text { Lower } \\
\text { bound }\end{array}$ & $\begin{array}{l}\text { Upper } \\
\text { bound }\end{array}$ & $\begin{array}{l}\text { Bellow the } \\
\text { lower bound }\end{array}$ & $\begin{array}{c}\text { Within the } \\
95 \% \mathrm{Cl}\end{array}$ & $\begin{array}{l}\text { Above the } \\
\text { Upper bound }\end{array}$ & $\begin{array}{l}\text { Bellow the } \\
\text { mean }\end{array}$ & $\begin{array}{c}\text { Above the } \\
\text { mean }\end{array}$ \\
\hline Factor (4) / (1) & 124 & 1.2112 & 1.1997 & 1.2227 & 47 & 31 & 46 & 61 & 63 \\
\hline Factor (3) / (5) & 124 & 1.2260 & 1.2152 & 1.2368 & 58 & 12 & 54 & 63 & 61 \\
\hline Factor (1) / (2) & 124 & 1.0361 & 1.0292 & 1.0430 & 50 & 23 & 51 & 63 & 61 \\
\hline \multicolumn{10}{|l|}{ Males } \\
\hline Factor (4) / (1) & 62 & 1.2180 & 1.1987 & 1.2373 & 24 & 18 & 20 & 28 & 34 \\
\hline Factor (3) / (5) & 62 & 1.2228 & 1.2082 & 1.2374 & 30 & 8 & 24 & 35 & 27 \\
\hline Factor (1) / (2) & 62 & 1.0422 & 1.0339 & 1.0505 & 24 & 14 & 24 & 26 & 36 \\
\hline \multicolumn{10}{|l|}{ Females } \\
\hline Factor (4) / (1) & 62 & 1.2044 & 1.1920 & 1.2168 & 21 & 14 & 27 & 33 & 29 \\
\hline Factor (3) / (5) & 62 & 1.2292 & 1.2132 & 1.2451 & 25 & 10 & 27 & 28 & 34 \\
\hline Factor (1) / (2) & 62 & 1.0300 & 1.0190 & 1.0410 & 24 & 16 & 22 & 37 & 25 \\
\hline
\end{tabular}

$95 \% \mathrm{Cl}, 95 \%$ confidence interval.

Source: Institution's data.

and women. The literature is inconclusive regarding this difference. We evaluated the shape of the knee based on the measurement factors and, in our sample, we did not find disparities between sexes. This finding is convergent with the study described by Piriou et al., ${ }^{27}$ who, after studying 376 femurs using a navigation system, could not demonstrate the sex influence on knee morphology.

The successful implementation of a femoral component during a TKA must include correct coronal, sagittal and rotational alignment, in addition to adequate bone coverage. ${ }^{17}$ The significant variation in the femoral shape revealed by the measurement factors makes these targets challenging to be achieved using conventional implants currently available. ${ }^{28}$ The size limitation was performed to make the manufacturing cost and stocking the implants feasible. ${ }^{3} \mathrm{New}$ technologies are adding precision and improving the cost-effectiveness of TKA surgery. ${ }^{29}$ Although still with a short-term follow-up, Culler et al. ${ }^{30}$ compared 126 patients' outcomes with customized implants and 122 using standardized implants. They found better results in rehabilitation and, even though the customized implant has a higher price, the final hospital cost was similar ( $p=0.913$ ), justified by the lower number of adverse events.

The use of reliable methods is essential for medical research, and every instrument or evaluation method must have its precision and reproducibility validated. The reliability of the method could have been tested through an intra-observer analysis. However, in a previous study, ${ }^{31}$ the main author (FBL) had already validated the method by blindly comparing the measurements using MRI with in-vivo measurements, the latter being considered the gold standard. The level of agreement found between the measures was excellent (intraclass correlation coefficient $\geq 0.80$ ). Thus, the method used did not require ratification.

The research has some limitations common to retrospective studies. Adjusting the measurements and their factors regarding the patients' body mass index could allow the shape of the femur to correlate with the biotype. However, this data was not available in the files. The anatomical axes of the limbs, which could influence the shape of the knees, were not considered in the analysis. The clinical indications that led to the examination were not documented, although all patients with previous surgery, tumors, or fractures in the knees were excluded from the study. 
Elderly patients are potential carriers of OA of the knee and may present the anatomical changes typical of this disease, such as the formation of osteophytes that would be a confounding factor in the measurements. The measurements were performed after simulating the distal femoral cut at $9 \mathrm{~mm}$ from the joint edge, eliminating this possible bias. As described by Cheng et al. ${ }^{32}$ and Kawak et al., ${ }^{33}$ the resected bone surface measurement, free of osteophytes and already prepared for prosthesis implementation, provides more reliable morphometric data for the design and improvement of the implant.

The study strengths were the evaluations of factors that made it possible to classify the distal femur variations far beyond broad or narrow. As described, the measurement method used was previously tested

\section{References}

1. Coimbra IB, Plaper PG, Campos GC. Generating evidence and understanding the treatment of osteoarthritis in Brazil. A study throught Delphi methodology. Clinics. 2019;74e722

2. Murphy L, Helmick CG. The impact of osteoarthritis in the United States: a population-health perspective: A population-based review of the fourth most common cause of hospitalization in U.S. adults. Orthop Nurs. 2012;31(2):85-91.

3. Schwechter EM, Fitz W. Design rationale for customized TKA: a new idea or revisiting the past? Curr Rev Musculoskelet Med 2012;5(4):303-8.

4. Nguyen LC, Lehil MS, Bozic KJ. Trends in total knee arthroplasty implant utilization. J Arthroplasty. 2015;30(5):739-42.

5. Sloan M, Premkumar A, Sheth NP. Projected volume of primary total joint arthroplasty in the US, 2014 to 2030 . J Bone Joint Surg Am. 2018;100:1455-60.

6. Ferreira MC, Oliveira JCP, Zidan FF, et al. Artroplastia total de joelho e quadril: a preocupante realidade assistencial do Sistema Único de Saúde brasileiro. Rev Bras Ortop. 2018;53(4):432-40.

7. Gillespie RJ, Levine A, Fitzgerald SJ, et al. Gender differences in the anatomy of the distal femur. J Bone Joint Surg Br. 2011;93(3):357-63.

8. Loures FB, de Araujo Goes RF, da Palma IM, et al. Anthropometric study of the knee and its correlation with the size of three implants available for arthroplasty. Rev Bras Ortop. 2016;51(3):282-9.

9. Bonnin MP, Schmidt A, Basiglini L, Bossard N, Dantony E. Mediolateral oversizing influences pain, function, and flexion after TKA. Knee Surg Sports Traumatol Arthrosc. 2013;21(10):2314-24.

10. Li K, Saffarini M, Valluy J, Desseroit MC, et al. Sexual and ethnic polymorphism render prosthetic overhang and undercoverage inevitable using off-the shelf TKA implants. Knee Surg Sports Traumatol Arthrosc. 2019;27(7):2130-9.

11. Dargel J, Michael JW, Feiser J, et al. Human knee joint anatomy revisited: morphometry in the light of sex-specific total knee arthroplasty. J Arthroplasty. 2011;26(3):346-53.

12. Triola MF. Introdução à Estatística. Rio de Janeiro: LTC; 2008. and validated, which guaranteed the measurements' reliability. ${ }^{31}$ The great interpersonal variation demonstrated by the study anticipates the surgeon's possible difficulties to precisely fit the prosthesis to the resected bone. Adequate adjustments to the shape and number of implants available can make the surgery more accurate and safer.

\section{Conclusion}

The shape of the distal femur presents great interpersonal variation, going beyond the simple division between wide or narrow. This variation is influenced by the patients' age, but not the sex. The implant manufacturer must considered these anatomical considerations for the new models to present a better adjustment with the knee's natural shape.

13. Kunze KN, Akram F, Fuller BC, et al. Internal Validation of a Predictive Model for Satisfaction After Primary Total Knee Arthroplasty. J Arthroplasty. 2019;34(4):663-70.

14. Yang B, Yu J-K, Zheng Z-Z, et al. Comparative study of sex differences in distal femur morphology in osteoarthritic knees in a Chinese population. PLoS One. 2014;9(2):e89394.

15. Bonnin MP, Saffarini M, Bossard N, et al. Morphometric analysis of the distal femur in total knee arthroplasty and native knees. Bone Joint J. 2016;98-B(1):49-57.

16. Lonner JH, Jasko JG, Thomas BS. Anthropomorphic differences between the distal femora of men and women. Clin Orthop Relat Res. 2008;466:2724-9.

17. Han $\mathrm{H}$, Oh S, Chang CB, et al. Anthropometric difference of the knee on MRI according to gender and age groups. Surg Radiol Anat. 2016;38(2):203-11.

18. Loures FB, Góes RFA, Sousa EB, et al. Intraoperative morphometric study of distal femur in Brazilian patients undergoing total knee arthroplasty. Plos One. 2020;15(5):e0233715.

19. Li K, Cavaignac E, Xu W, et al. Morphometric evaluation of the knee in Chinese population reveals sexual dimorphism and age-related differences. Int Orthop. 2018;42(10):2349-56.

20. Yao R, Lyons MC, Howard JL, et al. Does patellectomy jeopardize function after TKA? Clin Orthop Relat Res. 2013;471(2):544-53.

21. Papalia R, Zampogna B, Torre G, et al. Sarcopenia and its relationship with osteoarthritis: risk factor or direct consequence? Musculoskelet Surg. 2014;98(1):9-14.

22. Ha CW, Na SE. The correctness of fit of current total knee prostheses compared with intra-operative anthropometric measurements in Korean knees. J Bone Joint Surg Br. 2012;94(5):638-41.

23. Kuo AW, Chen DB, Wood J, et al. Modern total knee arthroplasty designs do not reliably replicate anterior femoral morphology. Knee Surg Sports Traumatol Arthrosc. 2019;27 [Ahead of Print]

24. Loures FB, Furtado Neto S, Pinto R de L, et al. Rotational assessment of distal femur and its relevance in total knee arthroplasty: analysis by magnetic resonance imaging. Radiol Bras. 2015;48(5):282-6. 


\section{Original article}

25. Mahfouz M, Abdel Fatah EE, Bowers LS, et al. Threedimensional morphology of the knee reveals ethnic differences. Clin Orthop Relat Res. 2012;470(1):172-85.

26. Pena SDJ. Reasons for banishing the concept of race from Brazilian medicine. Hist. Cienc Saude - Manguinhos. 2005;12(1):321-6.

27. Piriou P, Mabit C, Bonnevialle P, et al. Are gender-specific femoral implants for total knee arthroplasty necessary? J Arthroplasty. 2014;29(4):742-8.

28. Asseln M, Hänisch C, Schick F, et al. Gender differences in knee morphology and the prospects for implant design in tota knee replacement. Knee. 2018;25(4):545-58

29. Beal MD, Delagramaticas D, Fitz D. Improving outcomes in total knee arthroplasty-do navigation or customized implants have a role? J Orthop Surg Res. 2016;23:1
30. Culler SD, Martin GM, Swearingen A. Comparison of adverse events rates and hospital cost between customized individually made implants and standard off-the-shelf implants for total knee arthroplasty. Arthroplasty Today. 2017;3(4):257-63.

31. Loures FB, Carrara RJ, Góes RFA, et al. Anthropometric study of the knee in patients with osteoarthritis: intraoperative measurement versus magnetic resonance imaging. Radiol Bras. 2017;50(3):170-5.

32. Cheng CK, Lung CY, Lee YM, et al. A new approach of designing the tibial baseplate of total knee prostheses. Clin Biomech (Bristol, Avon). 1999 Feb;14(2):112-7.

33. Kwak D-S, Han S, Han CW, et al. Resected femoral anthropometry for design of the femoral component of the total knee prosthesis in a Korean population. Anat Cell Biol. 2010 Sep;43(3):252-9. 